\title{
A new design of bee cage for laboratory experiments: nutritional assessment of supplemental diets in honey bees (Apis mellifera)
}

\author{
Kai-Chieh Yang, Zhi-Wei Peng, Chun-Hsien Lin, Ming-Cheng Wu (1) \\ Department of Entomology, College of Agriculture and Natural Resources, National Chung Hsing University, Taichung, \\ Taiwan
}

Received 10 June 2020 - Revised 5 November 2020 - Accepted 9 December 2020

\begin{abstract}
We designed a cage that can maintain adult bees for 21 days with about $90 \%$ survival rate, in addition to facilitating the changing of sucrose syrup and beebread, and collection of live and dead bees without disturbing or releasing bees. The consumption rates of bee pollen diet and sucrose syrup for groups of 50-200 honey bees were recorded for 21 days after emergence. The bees consumed the bee pollen diet mainly at the age of 1-9 days. Regular consumption of sucrose syrup was observed among all bee groups throughout the 21 days. Furthermore, the nutritional responses of nurse bees - specifically, the expressions of major royal jelly protein 1 ( mrjpl) in the head and vitellogenin $(\mathrm{vg})$ in the abdomen - upon the provision of five single-supplemental diets were evaluated. We aimed to improve the usability of bee cages by elucidating the food consumption of bees and the relationship between nutritional gene expression and the ingestion of each single-protein diet.
\end{abstract}

Bee cage / Bee pollen substitutes / Major royal jelly protein 1 / Vitellogenin

\section{INTRODUCTION}

Honey bees greatly contribute to the agricultural economy. However, their existence has been threatened by multiple factors, such as pesticides, pathogens, and parasitic mites (Beaurepaire et al. 2020; Steinhauer et al. 2018; Wright et al. 2018). In our previous study, we found that honey bee larvae exposed to sublethal doses of imidacloprid have a downregulated gene expression of major royal jelly proteins (MRJPs) relative to adult insects (Wu et al. 2017). This might lead to nutritional deficiencies in larvae, indicating that pesticides prolong larval development (Wu et al. 2011). Nutritional stress due to poor food source, pesticide exposure, and pathogenic infection has been proposed as the major cause of loss of honey

Corresponding author: M. Wu, mcwu@nchu.edu.tw Manuscript editor: James Nieh bee colonies (Branchiccela et al. 2019; Goulson et al. 2015; Ricigliano et al. 2019; Wright et al. 2018).

Nutrition is the central unit of physiological processes. For honey bee larvae and adults in particular, appropriate nutrition promotes a virtuous cycle in physiological operations, such as in development, function, and survival, resulting in the good health of the colony (Wright et al. 2018). Honey bees obtain nutrition from their diet, i.e., nectar and pollen. Nectar is the main source of carbohydrates that provide energy to workers, whereas pollen is the main source of proteins, amino acids, lipids, sterols, vitamins, and minerals - which are required for brood rearing, maturation, and development (Brodschneider and Crailsheim 2010; Wright et al. 2018). During periods of food dearth, the carbohydrate demand of bee colonies can be satisfied by providing sucrose syrup, whereas the protein demand can 
be fulfilled by providing bee pollen substitutes, an alternative protein source. Another reason motivating the development of bee pollen substitutes is that unknown sources of bee pollens may contain residues of pesticides and pathogens. The common alternative protein sources used for bee pollen substitutes are soybean flour, yeast extract, egg yolk, milk, and other products with high protein content. Such bee pollen substitutes are generally made of different ratios of alternative proteins and have nutritional effects similar to those of bee pollen on honey bees. For example, as reported by Cremonz et al. (1998), a mixture of soybean flour and sugarcane yeast can stimulate vitellogenin expression in nurse bees. van der Steen (2007) reported that a mixture of soya flour, beer yeast flour, caseinate flour, and whey protein flour can be readily consumed by bees, where this mixture has nutritional effects similar to those of bee pollen on bee colonies. De Jong et al. (2009) reported two commercial bee pollen substitutes to be as capable as bee pollen is in increasing hemolymph protein levels in honey bees; Peng et al. (2012) demonstrated that bee pollen substitutes comprising different ratios of protein supplements can stimulate the development of the hypopharyngeal glands (HPGs) of nurse bees.

To relieve the nutritional stress of honey bees, we are exploring diet supplements such as highprotein ingredients, herb extracts, and micronutrients. Thus far, bee scientists have estimated the nutritional value of various bee pollen substitutes composed of a mixture of soy flour, brewer's yeast, and other high-protein supplements, and some formats of the bee pollen substitute have been regularly used by beekeepers (Amro et al. 2016; Cremonz et al. 1998; De Jong et al. 2009; Peng et al. 2012; van der Steen 2007). However, data regarding the nutritional effects of a single specific source of protein on caged bees are not informative (Williams et al. 2013). Therefore, we estimated the influence of each ingredient of soy flour, yeast extract, peptone, egg yolk, and milk protein, compared with bee pollen, on the nutritional physiology of nurse bees.

In addition to estimating the effects of diet supplements on the nutritional status of honey bees, we are also surveying cage systems for maintaining honey bees under laboratory conditions. Many types of cages have been developed for bee research (Bosua et al. 2018; Huang et al. 2014; Williams et al. 2013). These cages have been constructed at different sizes and with different feeders using various materials, such as wood (Altaye et al. 2010), polymethyl methacrylate (Grozinger et al. 2003; Tosi and Nieh 2017), polycarbonate (Aumer et al. 2018; Köhler et al. 2013), cardboard (Dechaume Moncharmont et al. 2003), and plastics (Gregorc et al. 2018). All such cages have their unique advantages and disadvantages for bee research.

Through this study, we aimed to improve previous rearing cages for laboratory experiments to maintain adult Apis mellifera and to assess the effects of dietary supplements on nutrition-related gene expressions. The gene encoding major royal jelly protein 1 (MRJP1) plays roles as nutritional storage and physiological development protein in honey bee (Buttstedt et al. 2013; Buttstedt et al. 2014). Additionally, the gene vitellogenin (vg) encodes a nutritional storage and regulatory protein that has been used as a nutritional index of honey bees (Cremonz et al. 1998; Di Pasquale et al. 2013; Huang et al. 2014). We elucidate the effects of different single-diet supplements, such as lactose-free milk powder, peptone powder, soybean flour, yeast extract powder, and egg yolk powder, on the expressions of mrjpl and $v g$, thereby creating a foundation for a more holistic understanding of bee nutrition.

\section{MATERIALS AND METHODS}

\subsection{Honey bees}

Hives of honey bees (A. mellifera ) were maintained on the rooftop of a building in National Chung Hsing University (NCHU), Taichung. Each colony, containing a young normal egglaying queen, had a working population of eight frames of comb with larvae, pupae, honey, and pollen; the healthy colonies were maintained in accordance with standard beekeeping practices.

\subsection{Bee pollens}

The polyfloral bee pollens were collected with a pollen trap in the university apiary from March 
to May (spring season in Taiwan), and it contained at least five types of pollen: Bidens pilosa, Liquidambar formosana, Bischofia javanica, Bombax ceiba, and Acrcocomia aculeata.

\subsection{Cage design}

The cages $(15 \times 10 \times 15 \mathrm{~cm}$; volume $2250 \mathrm{~mL})$ made by using acrylic plastic $(3 \mathrm{~mm})$ were designed for maintaining groups of 50-200 honey bee workers (Figure 1). The front side of the cage has a hole of diameter $10 \mathrm{~cm}$, which allows easy access through silk stockings and tissue papers. The right and left bottom corners have holes measuring $2 \times 2 \mathrm{~cm}$ and $1.6 \times 6 \mathrm{~cm}$ to facilitate the feeding of sugar syrup and beebread, respectively. Additionally, a thin $(2 \mathrm{~mm})$ piece of acrylic plastic $(15 \times 9.8 \mathrm{~cm})$ with filter paper can be slid into the cage from the bottom-left side and easily removed for cleaning. The top side contains nine small holes ( $3 \mathrm{~mm}$ in diameter) for ventilation.

A small bird feeder $(75 \mathrm{~mL})$ with a hole measuring $1.5 \times 1 \mathrm{~cm}$ is used as a syrup feeder; it can be fitted into the hole at the right bottom corner. This type of syrup feeder has no problems with leakage and can be easily manipulated. Additionally, a petri dish $(40 \times 10 \mathrm{~mm})$ that can hold at least $10 \mathrm{~g}$ of artificial beebread and that can be inserted into the cage from the hole at the left bottom corner was used as the beebread feeder. It can be easily withdrawn and replaced with fresh beebread.

\subsection{Survival and consumption measurements in the newly designed cage}

The sealed brood frames were removed from the bee colony and maintained in the insect growth chamber (temperature: $34{ }^{\circ} \mathrm{C}$, relative humidity: $60 \% \pm 10 \%$, dark). Newly emerged bees were randomly collected from the frame within $12 \mathrm{~h}$ of emergence and introduced to the newly designed cage for growth evaluation. Each cage was replicated four times using different honey bee colonies. All cages were maintained in the insect growth chamber; $50 \%$ sucrose solution was placed in the syrup feeder. Bee pollen diet for this experiment was prepared by mixing polyfloral bee pollens with $50 \%$ sucrose solution at a mass ratio of 3:1 (bee pollen: $50 \%$ sucrose solution) and placed in a petri dish. Both diets were changed and recorded for consumption weight every 3 days. Bee mortality was recorded every day until 21 days after emergence.

\subsection{Evaluation of supplemental diet feed}

The tested dietary supplemental sources-soybean flour (from local farmers), yeast extract powder (A8569; Biomatik, Wilmington, DE, USA), peptone powder (A8550, Biomatik, USA), egg yolk powder (from Chinyi, Taiwan), and lactose-free milk powder (Nestle, Nunspeet, Netherlands) — were purchased from the respective manufacturers. Protein concentration of each diet supplement including polyfloral bee pollen was estimated by BCA protein assay reagent kit (Pierce, Rockford, IL, USA). One hundred milligrams of each powdered supplement was prepared in $10 \mathrm{mM}$ Tris buffer $(\mathrm{pH} \mathrm{7.0)}$. The solution of each supplement was centrifuged $\left(12,000 \mathrm{~g}, 10 \mathrm{~min}, 25^{\circ} \mathrm{C}\right)$ and the supernatant was used for protein quantification assay which performed with a 96-well microplate by an ELISA spectrophotometer (Multiskan EX, Labsystem, Finland). Bovine serum albumin was used as the standard. Protein concentration of each diet supplement was listed in Supplementary Table 1. Each diet including bee pollen was prepared as a $40 \%$ supplement patty gel ( $0.5 \%$ agar) which was made by mixing 4 parts of supplement and 6 parts of $50 \%$ sucrose solution. Adequate amount of agarose was added in 50\% sucrose solution and then heated until the agarose is completely dissolved. Cool the agarose/sucrose solution to $45^{\circ} \mathrm{C}$, then mix it with supplement well, and pour it into a petri dish $\left(40 \times 10 \mathrm{~mm}^{2}\right)$ to form a $40 \%$ supplement patty gel.

Four honey bee colonies were selected for this experiment. The sealed brood frames were collected from the bee colonies and maintained in the insect growth chamber. Newly emerged bees were randomly collected from the frame within $12 \mathrm{~h}$ of emergence, and for nutritional evaluation, 30 of the bees were introduced to the cage equipped with the patty gel weighing $5 \mathrm{~g}$ and $50 \%$ sucrose 
(a)

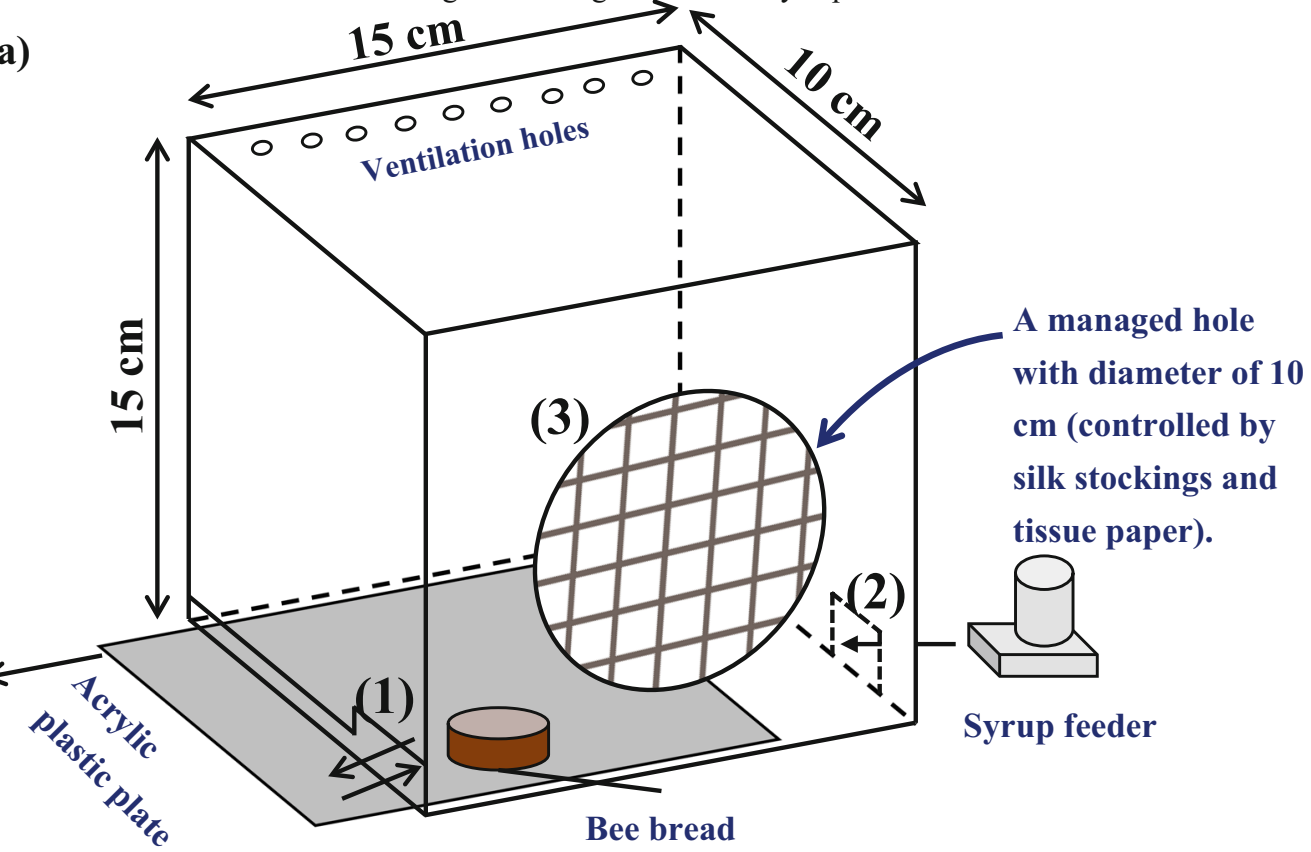

(b)

Total volume: $2250 \mathrm{~mL}$

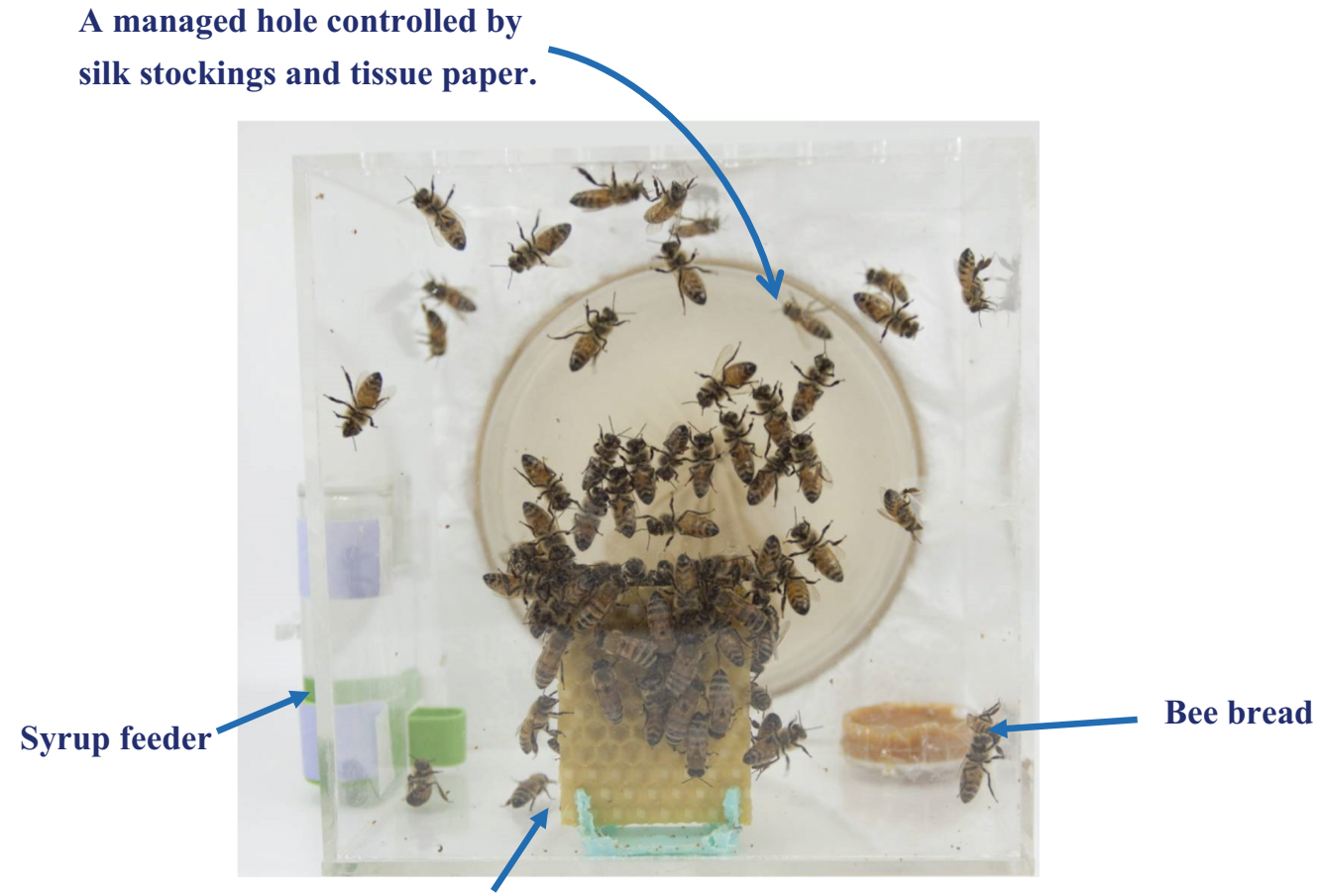

Beeswax foundation

Figure 1. Acrylic plastic cage. a Details of cage design; label (1) indicates the hole for the feeding of beebread, label (2) indicates the hole for the feeding of sugar syrup, label (3) indicates the managed hole controlled by silk stockings and tissue paper. b Actual cage view. In total, 100 bees were kept in the cage and provided with food (50\% sucrose and beebread) and beeswax foundation (photo taken by Mr. Chun-Peng Kuo). 
solution. All cages were maintained in the aforementioned insect growth chamber. The foods (50\% sucrose solution and patty gel) were changed every 3 days. Bee mortality was recorded every day until 6 days after emergence. On day 6 , the caged bees were anesthetized using $\mathrm{CO}_{2} ; 10$ bees were randomly collected from the cage for dissection, and their heads and abdomens were weighed by using analytical Lab balance with a readability of $0.1 \mathrm{mg}$ (Sartorius BSA124S-CW, Goettingen, Germany). The weighed samples were then subjected to RNA purification.

\subsection{RNA purification}

Ten heads and abdomens of 6-day-old workers from the cage rearing system were collected and immediately ground in 2-4 mL of TRIzol reagent (Thermo Fisher Scientific, Waltham, MA, USA). Total RNA was extracted using TRIzol reagent combined with a PureLink RNA Mini Kit (Thermo Fisher Scientific) to obtain high-quality RNA. For the complete removal of contaminating DNA from the RNA preparations, the samples were processed using a TURBO DNA-free Kit (Thermo Fisher Scientific), according to manufacturer instructions. A Qubit fluorometer (Thermo Fisher Scientific) was used to determine RNA quantity.

\subsection{Quantitative RT-PCR}

The reverse transcription step was performed using $1 \mu \mathrm{g}$ of total RNA and an iScript cDNA Synthesis Kit (Bio-Rad, Hercules, CA, USA). Gene-specific primers are listed in Supplementary Table 2. Each qRT-PCR reaction in a 96-well microtiter plate contained $10 \mu \mathrm{L}$ of $2 \times$ iQ SYBR Green Supermix (Bio-Rad), $2.5 \mu \mathrm{L}$ of $1.6 \mu \mathrm{M}$ of each gene-specific primer, and $5 \mu \mathrm{L}$ of diluted cDNA in a final volume of $20 \mu \mathrm{L}$. PCR was performed using an iCycler iQ5 Detection System (Bio-Rad). The cycling program comprised an initial step at $95^{\circ} \mathrm{C}$ for $3 \mathrm{~min}$, followed by 40 cycles at $95{ }^{\circ} \mathrm{C}$ for $10 \mathrm{~s}$ and at $59{ }^{\circ} \mathrm{C}-61{ }^{\circ} \mathrm{C}$ (depending on the Tm value of the primers) for $30 \mathrm{~s}$. A melting curve analysis of the final amplified product was performed by taking continuous readings over increasing temperatures from $55^{\circ} \mathrm{C}$ to $95^{\circ} \mathrm{C}$ to ensure amplification specificity.
The qRT-PCR data were collected using the BioRad iQ5 2.0 Standard Edition Optical System Software V2.0 (Bio-Rad) and normalized to the reference gene actin, GB44311 (Lourenço et al. 2008; Scharlaken et al. 2008). The relative gene expression data were analyzed using the $2^{-\Delta \Delta C \mathrm{~T}}$ method (Livak and Schmittgen 2001). Each qRTPCR experiment was performed using four independent biological replicates, with three technical replicates for each experiment.

\subsection{Statistical analysis}

All statistical analyses were conducted using Statistica (StatSoft, Inc., Tulsa, OK, USA). The cage survival data were analyzed using KaplanMeier survival curve, and Gehan's Wilcoxon paired tests were used to test for differences between groups of different bee numbers. The head and abdominal weights of honey bee data were analyzed by using ANOVA with Tukey HSD (honestly significant difference) method to perform post hoc comparisons.

\section{RESULTS}

\subsection{Survival and food consumption measurements}

To evaluate the practicality of the cage, groups of 50,100, and 200 newly emerged bees were placed in the cages containing a nest foundation, bee pollen beebread, and 50\% sucrose solution. During the course of the 21-day experiment, the cumulative survival rates and food consumption rates of the honey bees in the three tested groups were recorded. The cumulative 21-day survival rate shown significantly differs between the groups of 50 and 200, and 100 and 200 bees (Figure 2 and Table I). As detailed in Table II and Figure 2, a higher relative volume of honey bees in the cage was associated with a higher survival rate $(50$ bees, $95 \% \pm 2.6 \% ; 100$ bees, $93.5 \% \pm 3.0 \%$; and 200 bees, $88.9 \% \pm 8.2 \%$ ).

Food (bee pollen and sugar solution) consumption was recorded once every 3 days, when the food was changed. As presented in Table II, the total consumption of food was proportional to the bee number: that is, for the groups of 50,100, and 


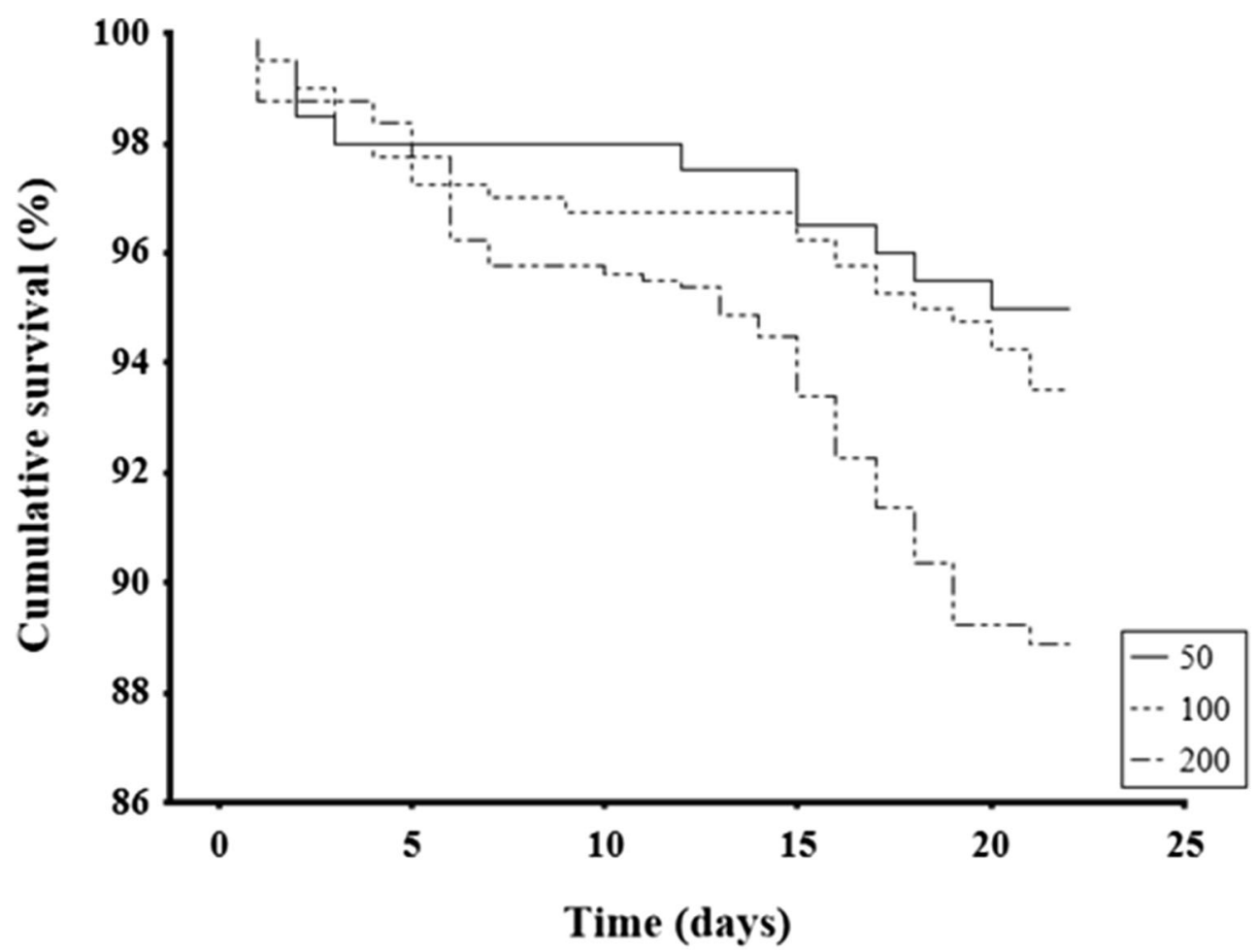

Figure 2. Cumulative survival rate of worker bees in acrylic plastic cage. Worker bees in the groups of 50, 100, and 200 bees were fed sugar syrup and pollen beebread and were incubated at $34{ }^{\circ} \mathrm{C}$ on a piece of beeswax foundation. Each point represents the cumulative survival rate $(N=4$ cages from four colonies for each group of 50,100, and 200 bees in the tests).

200 bees, the total bee pollen consumptions were $2.6 \pm 0.3 \mathrm{~g}, 5.3 \pm 0.2 \mathrm{~g}$, and $6.8 \pm 1.5 \mathrm{~g}$, respectively, and the total sugar syrup consumptions were $44.1 \pm 4.0 \mathrm{~g}, 116.1 \pm 16.7 \mathrm{~g}$, and $184.0 \pm$ $10.3 \mathrm{~g}$, respectively (corrected for evaporative loss). The bee pollen diet was mainly consumed

Table I. Survival was compared across different groups of individual numbers using Gehan's Wilcoxon paired test and resulting $p$ values are presented here (italic values indicate existing statistical significance, $p<0.05$ )

\begin{tabular}{lccc}
\hline Individual numbers & 50 & 100 & 200 \\
\hline 50 & & 0.48 & 0.01 \\
100 & 0.48 & & 0.01 \\
200 & 0.01 & 0.01 & \\
\hline
\end{tabular}

by 1 to 9-day-old bees, accounting for approximately $70 \%$ of the total bee pollen diet consumed in 21 days ( 50 bees: $76.9 \%, 100$ bees: $76.2 \%, 200$ bees: $69.3 \%$ ), with the highest mean consumption occurring on days 4-6(Figure $3 a$ and $b$ ). The bee pollen diet consumption per bee dropped from the highest peak of approximately $20 \mathrm{mg} / 3$ days at day 6 to approximately $2 \mathrm{mg} / 3$ days at day 15 . Bees aged 10-21 days consumed approximately $20-30 \%$ of the bee pollen diet during the 21-day period (50 bees, 23.1\%; 100 bees, 23.8\%; 200 bees, $30.7 \%$ ) (Figure $3 a$ and $b$ ).

Sugar consumption by caged bees was measured by determining the change in the weight of $50 \%$ sucrose syrup over a period of 3 days. Bees in the three groups $(50,100$, and 200 bees) consumed approximately $100 \mathrm{mg}$ of sugar solution during the first 3 days. Such consumption gradually increased to approximately 
Table II. Relative volume per bee, percentage survival rate after 21 days, and total consumption of diets in 21 days

\begin{tabular}{lllll}
\hline Number of bees & $\begin{array}{c}\text { Volume } \\
(\mathrm{mL} / \mathrm{bee})\end{array}$ & $\begin{array}{c}\text { 21-days cumulative } \\
\text { survival rate }(\%)\end{array}$ & $\begin{array}{c}\text { Total consumption } \\
\text { of pollen in 21 days }(\mathrm{g})\end{array}$ & $\begin{array}{c}\text { Total consumption } \\
\text { of sugar solution in } \\
\text { 21 days (g) }\end{array}$ \\
\hline 50 & 45 & $95 \pm 2.6$ & $2.6 \pm 0.3$ & $44.1 \pm 4.0$ \\
100 & 22.5 & $93.5 \pm 3.0$ & $5.3 \pm 0.2$ & $116.1 \pm 16.7$ \\
200 & 11.3 & $88.9 \pm 8.2$ & $6.8 \pm 1.5$ & $184.0 \pm 10.3$ \\
\hline
\end{tabular}

$150 \mathrm{mg}$ per bee for the group of 50 bees and to approximately $220 \mathrm{mg}$ per bee for the groups of 100 and 200 bees on days 7-9; it then declined to approximately $100-150 \mathrm{mg}$ per bee in all the three groups on days 13-21(Figure 3c).

(a)

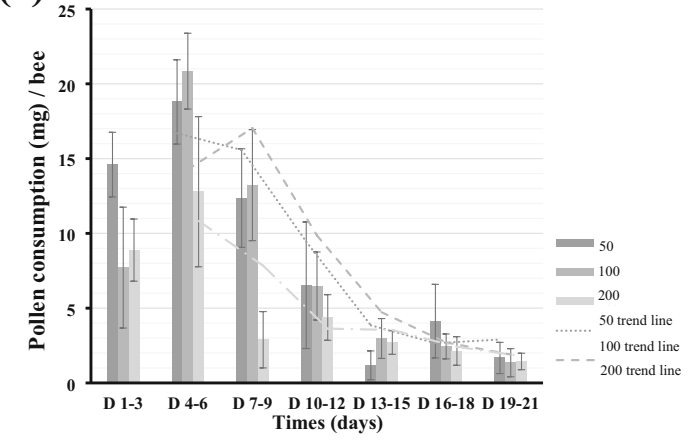

(b)

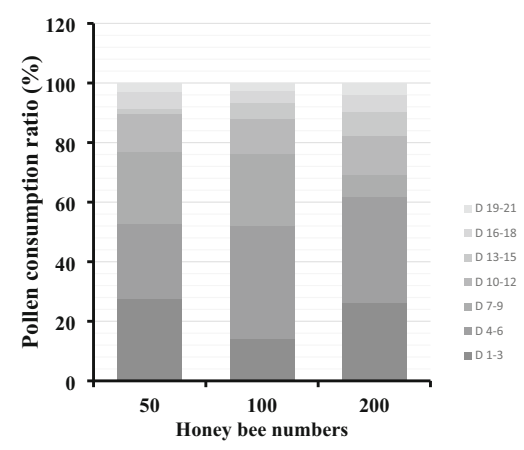

Typically, a uniform sugar consumption ratio was observed during the 21 days after emergence, that is, bees in all the three groups consumed about $14 \%$ of sugar solution every 3 days (Figure 3d). (c)

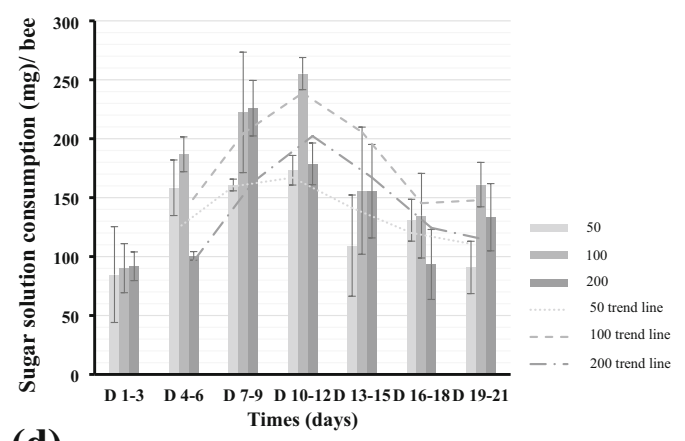

(d)

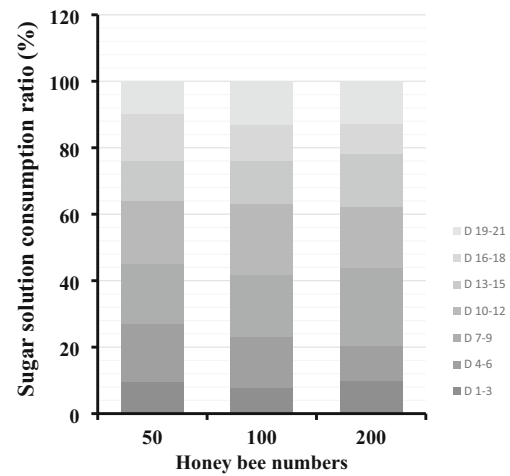

Figure 3. Consumption of diets over 3-day intervals by caged honey bees over 21 days. a Pollen consumption (mg per bee) in the group of 50, 100, and 200 worker bees. Each bar represents mean \pm standard deviation. Trend line indicates the moving average of two periods. b Pollen consumption ratio represents the weight of pollen consumed for 3 days over the total weight of pollen consumed for 21 days. c Sugar solution consumption (mg per bee) in the group of 50,100, and 200 worker bees. Each bar represents mean \pm standard deviation. Trend line indicates the moving average of two periods. d Sugar solution consumption ratio represents the weight of the solution consumed for 3 days over the total weight of the solution consumed for 21 days. $N=4$ cages from four colonies for each group of 50,100 , and 200 bees in the tests. 


\subsection{Nutritional evaluation after feeding of supplemental diet}

Five diet supplements that have been commonly recognized as high-nutrient diets, namely lactosefree milk powder, peptone powder, soybean flour, yeast extract powder, and egg yolk powder, were chosen for the nutritional assay. Because lactose is poisonous for bees, lactose-free milk was used in this study. The milk powder contained $11.1 \%$ of protein, $25.8 \%$ of fat (16\% linoleic acid and $1.9 \%$ alpha-linolenic acid), and 58\% of carbohydrates with vitamins and minerals. Peptone - containing at least $18.4 \%$ of protein, having enzymatic digestion of protein, and being an excellent natural source of amino acids, peptides, and proteins - has been commonly used for the preparation of bacterial culture media. The soybean flour was prepared by a local farmer, and it had a protein content of $242.3 \mathrm{mg}$ protein/g. Yeast extract, the product of yeast cells, which not only has a high protein content (336.2 $\mathrm{mg}$ protein $/ \mathrm{g}$ ) but also is a rich source of vitamin B complex, is extensively used as a nutritional resource for bacterial culture media. The egg yolk contained $33.3 \%$ protein, $55.8 \%$ fat, and $3.6 \%$ carbohydrate. Polyfloral bee pollen and these five diet supplements were prepared using 50\% sucrose solution as a $40 \%$ patty gel.

As detailed in Supplementary Table 1, the six diets have a protein content ranging widely at 100 $400 \mathrm{mg}$ protein $/ \mathrm{g}$, resulting in the prepared $40 \%$ diet patty containing $4 \%, 7 \%, 10 \%, 13 \%, 13 \%$, and $16 \%$ protein from lactose-free milk, peptone, soybean, yeast extract, egg yolk, and polyfloral bee pollen patty, respectively. Each diet patty was fed to newly emerged bees and changed every 3 days.

After 6 days of feeding, the heads and abdomens of worker bees were collected for weighing and subjected to further RNA extraction for gene expression analysis. The head weight of the bees was approximately $10.6 \mathrm{mg}$, and the weight did not significantly differ between the bee pollen diet and the other five diets - after the bees had consumed the supplemental diet for 6 days (ANOVA, $F_{5,18}=0.35, P=0.8738$, Figure 4a). As illustrated in Figure $4 b$, the abdominal weight of bees that were fed diets containing milk, soybean flour, and yeast was approximately 48.8, 44.6, and $44.4 \mathrm{mg}$, respectively, which was greater than the abdominal weights of bees fed diets consisting of bee pollen and yolk. Bees fed peptone had the lowest abdominal weight of approximately $34.0 \mathrm{mg}$. However, compared with bees fed the bee pollen diet, those fed the five diet supplements did not significantly differ in their abdominal weights (ANOVA, $F_{5}$, $18=1.24, P=0.3313$, Figure $4 \mathrm{~b}$ ).

We profiled the mRNA expression of the nutrition-related genes major royal jelly protein 1 ( $m r j p 1)$, in the head, and vitellogenin ( $v g$ ), in the abdomen, after the honey bees were fed the six diets for 6 days. Following normalization with the reference gene actin and comparison with the $\Delta \mathrm{Ct}$ value from the bee pollen-feeding group, the relative gene expression can be classified into the two levels of higher and lower relative to the bee pollen-feeding group. As the gene expression of bees from the four tested colonies exhibited wide variation, we present the relative gene expressions in a heat map module. As shown in Table III, compared with bee pollen feed, yeast extract powder feed could regularly upregulate the mrjpl expression of bees by approximately 13 fold, and all bees from the four colonies responded positively to yeast extract feed. Feeds containing peptone and soybean could stimulate mrjp1 expression; however, only three out of the four colonies responded positively to both these feeds. Yolk and milk feeds increased the expression of mrjp1 in only two and one colonies, respectively. Diets can be ranked according to the number of colonies that exhibited increased mrjp1 expression, relative to the bee pollen diet, as follows: yeast extract powder $>$ peptone powder $>$ soybean flour $>$ yolk powder $>$ milk powder (Table III).

The expression of $v g$ in the bees from colony III did not increase in response to the nutritional stimuli of all five diets, relative to the bee pollen diet (Table III). However, feeds with yeast and peptone could stimulate $v g$ expression in the bees from colonies I, II, and IV by approximately 1.3to 5.8-fold. Feeds with milk and yolk increased the $v g$ gene expression in the bees from colonies I and II by 1.3- to 1.5-fold and 2.5- to 6.0-fold, respectively. Soybean feed exhibited a slightly lower effect on $v g$ gene expression; only bees from colony II exhibited an increased (2.9-fold) expression of the gene after the ingestion of soybean feed. Diets that stimulated $v g$ expression can be ranked as follows: yeast extract powder/ 
(a)

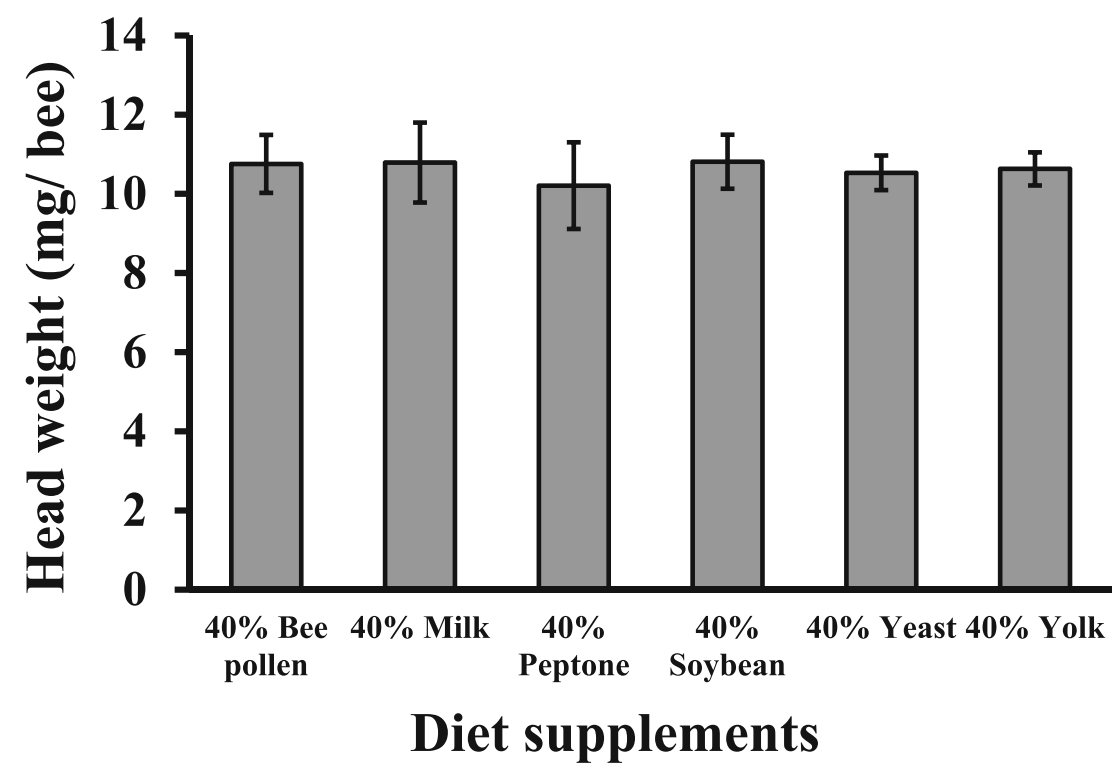

(b)

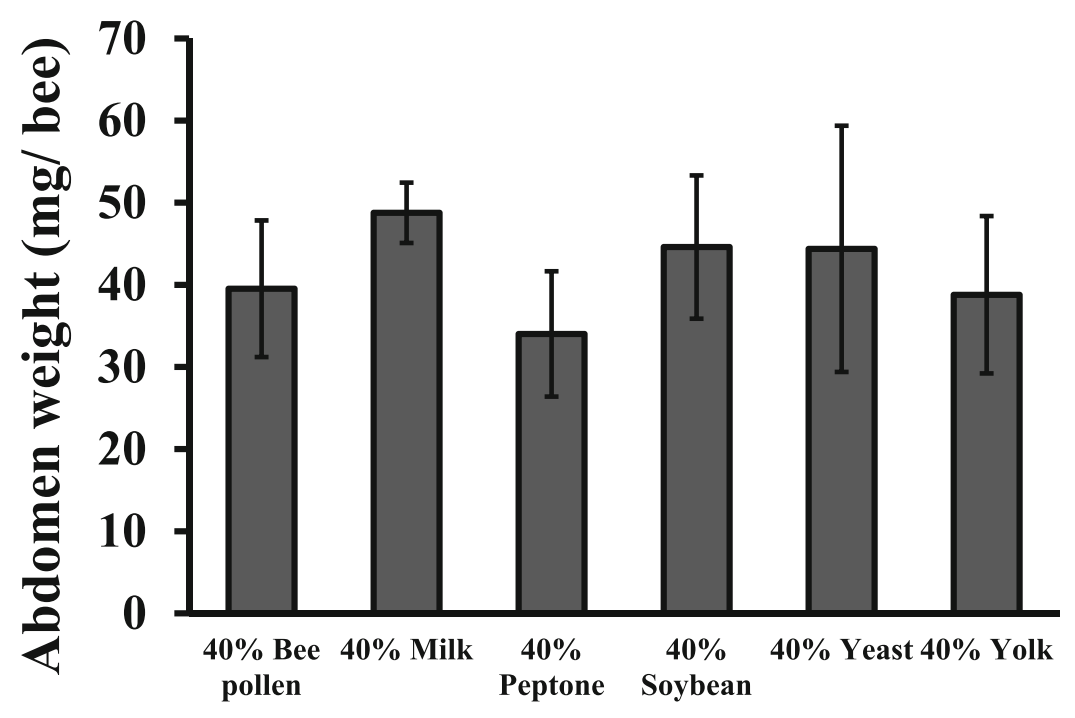

\section{Diet supplements}

Figure 4. Effect of diet supplements on head and abdominal weights of honey bees. a Head weight (mg/ bee) was calculated by weighing the heads of five bees from one cage. b Abdominal weight (mg/ bee) was calculated by weighing the abdomens of five bees from one cage. Each bar represents mean \pm standard deviation $(N=4$ cages from four colonies). The data of head and abdominal weights were analyzed by using ANOVA. There was no significant difference in the head weight (ANOVA, $F_{5,18}=0.35, P=0.8738$ ) and the abdominal weight (ANOVA, $\left.F_{5,18}=1.24, P=0.3313\right)$ among diet supplement treatments. 
Table III. a qRT-PCR analysis of mrjp1 expression in the heads, and $\mathbf{b} v g$ expression in the abdomens of honey bees fed six supplemental diets. RNA samples from the heads and abdomens of 6-day-old worker bees fed different supplemental diets since they emerged were prepared for qRT-PCR. The relative gene expression was analyzed using the $2^{-\Delta \Delta C \mathrm{~T}}$ method and the relative gene expression level is shown using different colors: dark gray represents a gene expression more than that observed in the bee pollen group, and light gray represents a gene expression less than that observed in the bee pollen group.

\begin{tabular}{lllllll}
\hline & & & & & \\
Colony & Bee pollen & Milk & Peptone & Soybean & Yeast & Yolk \\
I & 1.00 & 0.76 & 15.10 & 1.21 & 4.98 & 2.17 \\
II & 1.00 & 0.59 & 451.94 & 1.31 & 3.01 & 1.20 \\
III & 1.00 & 0.03 & 0.02 & 5.83 & 15.74 & 0.27 \\
IV & 1.00 & 17.07 & 3.83 & 0.02 & 28.38 & 0.25 \\
& & & (b) & & & \\
Colony & Pollen & Milk & Peptone & Soybean & Yeast & Yolk \\
I & 1.00 & 1.49 & 3.05 & 0.84 & 2.08 & 2.56 \\
II & 1.00 & 1.33 & 5.83 & 2.92 & 5.38 & 6.02 \\
III & 1.00 & 0.16 & 0.08 & 0.41 & 0.15 & 0.68 \\
IV & 1.00 & 0.42 & 1.33 & 0.36 & 2.44 & 0.75 \\
Colony & Bee pollen & Milk & Peptone & Soybean & Yeast & Yolk \\
I & 1.00 & 1.49 & 3.05 & 0.84 & 2.08 & 2.56 \\
II & 1.00 & 1.33 & 5.83 & 2.92 & 5.38 & 6.02 \\
III & 1.00 & 0.16 & 0.08 & 0.41 & 0.15 & 0.68 \\
IV & 1.00 & 0.42 & 1.33 & 0.36 & 2.44 & 0.75 \\
\hline
\end{tabular}

peptone powder $>$ yolk powder $>$ milk powder $>$ soybean flour (Table III).

\section{DISCUSSION}

Variations in the compositions of honey bee colonies - with respect to proportions of food, eggs, larvae, pupae, and adult bees - as well as changes in temperature and humidity inside and outside the beehive may affect the physiological responses of honey bees, rendering experiments involving honey bee colonies difficult. Therefore, cages were developed for maintaining adult worker bees under controlled conditions. Using caged bees can provide a detailed insight into the effects of various biotic and abiotic factors on the survival, behavior, and physiological development of honey bees - such as with respect to defense behavioral interactions (Elzen et al. 2001), trophallaxis behavior (Brodschneider et al. 2017), diseases (MartinHernandez et al. 2009), nutritional requirements (Altaye et al. 2010; Omar et al. 2017), and pesticidal effects (Wu et al. 2017).
Many types of cages have been developed to evaluate the survival of honey bees (Bosua et al. 2018; Huang et al. 2014). Among these, the disposable plastic cup helps achieve the longest survival curve for bees; moreover, it is inexpensive and transparent (Evans et al. 2009; Huang et al. 2014). This type of cage is useful for short-term experiments, such as toxicity assessment for pesticides sprayed on bees. However, the design of the disposable plastic cup poses a challenge for assessing nutritional gene expressions, royal jelly production, and comb construction. In such experiments, groups of 50-200 bee workers have to be sustained in the cage for 6-15 days. Therefore, we have improved the cage with a few new design choices. First, we added a small hole on the side for easily changing the beebread without disturbing the bees, where the beebread must be changed every 3 days to prevent mildew formation. Second, we added another small hole for holding the sugar syrup feeder. We replaced the syringe-type gravity-fed syrup feeders with water dispenser-like syrup feeders. The water 
dispenser-like sugar syrup feeder works well and has no problems with leakage. Sugar solution leakage may make the cage surface sticky, which worsens bee health and mortality rate in the cage. Additionally, there are no drowned bees occurred in the feeder. Third, we designed the cage to be accessed from the front, thus allowing the cage to be managed through silk stockings. Stockings facilitate the withdrawal of live and dead bees without releasing the bees into external space. A tissue paper covered on the silk stockings can prevent quick loss of humidity and can maintain good air exchange rate in comparison with the cage designed with bottom ventilation hole. Additionally, the acrylic plastic material used for the cage has several advantages, as follows: (1) its transparency enables assessment of the behavior of the honey bees; (2) it is reusable, can be easily cleaned, and can be sterilized using ethanol or bleach. The survival rate of the cage we designed is higher than that of other standard cage studies (Bosua et al. 2018; Köhler et al. 2013). This probably is contributed by the new designed components of the cage mentioned above.

The survival rate of the cage decreases from 95 to $88.9 \%$ when we increase bee population from 50 to 200 bees. The decreased survival rate probably is caused by cage fouling and wax production, both factors have been found that occur frequently in the high densities of bees, especially in the group of 200 bees. Cage fouling might lead to unhealthy environment, then reducing survival. Additionally, the energetic cost for wax production might contribute to the reduced survival (Bosua et al. 2018).

Nearly $80 \%$ of the bee pollen was consumed by caged honey bees aged 1-9 days. This finding is consistent with the findings of Omar et al. (2017) and Crailsheim et al. (1992), who used caged honey bees and colonies to investigate the effect of bee pollen diets on the nutritional physiology of honey bees. Each bee in the groups of 50, 100, and 200 bees consumed an average of 5.1, 4.6, and $2.7 \mathrm{mg}$ of bee pollen per day in the first 9 days after emergence. The average consumptions of the bee pollen diet between days 10 and 21 were 1.1 , 1.1 , and $0.9 \mathrm{mg}$ per bee per day for the groups of 50,100 , and 200 bees, respectively. Notably, the total consumption of bee pollen in 21 days was proportional to the number of bees; however, daily consumption of bee pollen decreased as the number of bees increased from 50 to 200 .

Each bee from the groups of 50, 100, and 200 bees consumed $40-55 \mathrm{mg}$ of sucrose syrup per day during the 21 days after emergence. This observation is similar to that from a study comparing various carbohydrate solutions consumed by 1200 caged bees, which revealed that each bee consumed an average of $60.0 \mathrm{mg}$ of sucrose syrup per day (Barker and Lehner 1978). Unlike bee pollen diets, no age-specific preference for sugar consumption was observed among the bees.

Based on currently available knowledge, the nutritional quality of bee pollens for honey bees can be determined by the metrics of protein content, essential amino acid composition, and essential fatty acid composition (Arien et al. 2020; Di Pasquale et al. 2013; Hendriksma et al. 2019; Liolios et al. 2016; Omar et al. 2017). Polyfloral bee pollens can typically meet nutritional content requirements and promote the nutritional physiology of honey bees - for example, the development of HPGs in nurse bees (Di Pasquale et al. 2013; Omar et al. 2017). A study by Di Pasquale et al. (2013) reported that polyfloral bee pollens with $17 \%$ protein content can maintain the normal nutritional physiology of honey bees by stimulating the HPG development and vitellogenin gene expression. Accordingly, we used the $40 \%$ polyfloral bee pollen patty with $16 \%$ protein content as a positive control to compare the effects of the other five diets on honey bees.

Body weight has been used to reflect the nutritional physiology of honey bees (Peng et al. 2012; Zheng et al. 2017). In this study, we divided the body weight of honey bees into their head and abdominal weights. Because the development of the HPGs is positively correlated with the head weight of the honey bee (Peng et al. 2012; Rahman et al. 2014), the head weight can indicate the development status of the HPGs. As shown in Figure $4 \mathrm{a}$, the head weight of honey bees that consumed any of the five diet patties was more than $10.0 \mathrm{mg}$, and the weight did not significantly differ from the head weights of the honeybees who consumed the bee pollen diet. A study by Manning (2006) demonstrated that caged bees with a head weight of more than $10 \mathrm{mg}$ have a well-developed HPG. This indicates that all diets that we assessed 
can stimulate the normal development of the HPG. However, quantification of head mrjpl transcripts of bees fed different diets yielded completely different results in different trials (Table III). Yeast extract powder, peptone powder, and soybean flour exhibited good stimulation of mrjp1 expression, implying that these three diets boost the nutrition of larval jelly. Further quantification of jelly protein requires confirmation in future studies.

Since the young caged bees typically do not excrete waste products in the cage, the abdominal weight of the bees can indicate the quantity of food intake in the gut. Only bees fed a $40 \%$ peptone diet exhibited the lowest abdominal weight (i.e., below $40 \mathrm{mg}$ ), which might be resulted from some side effects of more or less thirst, causing bees drink more or less sucrose solution. However, the quantification of abdominal $v g$ transcripts of bees fed different diets yielded different results in different trials. This finding slightly differs from the result for the stimulation of mrjpl expression, that is, soybean flour can positively promote mrjpl expression but cannot boost $v g$ expression (Table III). Bees from different colonies respond differently to the same diet, reflecting the inherent variability of individual bees. Based on the dietstimulation responses of mrjpl and $v g$ expression profiles, the top three diet candidates that can substitute bee pollen diet are yeast extract, peptone powder, and soybean flour. These results can be referred for preparation of bee pollen substitutes that provide adequate nutrition to bee colonies.

\section{SUPPLEMENTARY INFORMATION}

The online version contains supplementary material available at https://doi.org/10.1007 /s13592-020-00832-8.

This study was supported by the Ministry of Science and Technology (grant number 107-2313-B005-003-MY3) and Council of Agriculture (grant number 107AS-1.2.7-ST-a8), Taiwan.

\section{AUTHORS' CONTRIBUTIONS}

M.-C. Wu conceived of this research and designed experiments; Z.-W. Peng and M.-C. Wu participated in the design of cage; K.-C. Yang and C.-H. Lin performed experiments and analysis; K.-C. Yang and M.-C. Wu wrote the paper and participated in the revisions of it. All authors read and approved the final manuscript.

\section{FUNDING}

\section{DATA AVAILABILITY}

The data that support the findings of this study are available from the corresponding author on request.

COMPLIANCE WITH ETHICAL STANDARDS

Conflict of interest The authors declare that they have no conflict of interest.

Une nouvelle conception de cage à abeille pour les expériences de laboratoire: évaluation nutritionnelle des régimes complémentaires chez l'abeille (Apis mellifera ).

cage à abeille / substitut de pollen / protéine majeure de la gelée royale 1 / vitellogénine

Ein neues Design eines Bienenkäfigs für Laborexperimente: Ernährungswissenschaftliche Beurteilung von Nahrungsergänzungen bei Honigbienen (Apis mellifera)

Bienenkäfig / Pollenergänungsmittel / major royal jelly protein 1 / Vitellogenin

\section{REFERENCES}

Altaye SZ, Pirk CW, Crewe RM, Nicolson SW (2010) Convergence of carbohydrate-biased intake targets in caged worker honeybees fed different protein sources. J Exp Biol 213:3311-3318. doi:https://doi.org/10.1242 /jeb.046953

Amro A, Omar M, Ai-Ghamdi A (2016) Influence of different proteinaceous diets on consumption, brood 
rearing, and honey bee quality parameters under isolation conditions. Turk J Vet Anim Sci 40:468-475. doi:https://doi.org/10.3906/vet-1507-28

Arien Y, Dag A, Yona S, Tietel Z, Lapidot Cohen T, Shafir S (2020) Effect of diet lipids and omega-6:3 ratio on honey bee brood development, adult survival and body composition. J Insect Physiol 124:104074-104081. doi:https://doi.org/10.1016/j.jinsphys.2020.104074

Aumer D, Mumoki FN, Pirk CWW, Moritz RFA (2018) The transcriptomic changes associated with the development of social parasitism in the honeybee Apis mellifera capensis. Sci Nat-Heidelberg 105:22-33. doi:https://doi.org/10.1007/s00114-018-1552-2

Barker RJ, Lehner Y (1978) Laboratory comparison of high fructose corn syrup, grape syrup, honey, and sucrose syrup as maintenance food for caged honey bees. Apidologie 9:111-116. doi:https://doi.org/10.1051 /apido:19780203

Beaurepaire A, Piot N, Doublet V, Antunez K, Campbell E, Chantawannakul P, Chejanovsky N, Gajda A, Heerman M, Panziera D, Smagghe G, Yanez O, de Miranda JR, Dalmon A (2020) Diversity and global distribution of viruses of the western honey bee, Apis mellifera. Insects 11:239-263. doi:https://doi. org/10.3390/insects11040239

Bosua HJ, Nicolson SW, Archer CR, Pirk CWW (2018) Effects of cage volume and bee density on survival and nutrient intake of honeybees (Apis mellifera L.) under laboratory conditions. Apidologie 49:734-746. doi:https://doi.org/10.1007/s13592-018-0595-x

Branchiccela B, Castelli L, Corona M, Diaz-Cetti S, Invernizzi C, Martinez de la Escalera G, Mendoza Y, Santos E, Silva C, Zunino P, Antunez K (2019) Impact of nutritional stress on the honeybee colony health. Scientific reports 9:10156-10166. doi:https://doi. org/10.1038/s41598-019-46453-9

Brodschneider R, Crailsheim K (2010) Nutrition and health in honey bees. Apidologie 41:278-294. doi:https://doi. org/10.1051/apido/2010012

Brodschneider R, Libor A, Kupelwieser V, Crailsheim K (2017) Food consumption and food exchange of caged honey bees using a radioactive labelled sugar solution. PLoS One 12:e0174684-e0174702. doi:https://doi. org/10.1371/journal.pone.0174684

Buttstedt A, Moritz RF, Erler S (2013) More than royal food- Major royal jelly protein genes in sexuals and workers of the honeybee Apis mellifera. Front Zool 10:1-10. doi:https://doi.org/10.1186/1742-9994-10-72

Buttstedt A, Moritz RF, Erler S (2014) Origin and function of the major royal jelly proteins of the honeybee (Apis mellifera ) as members of the yellow gene family. Biol Rev Camb Philos Soc 89:255-269. doi:https://doi. org/10.1111/brv.12052

Crailsheim K, Schneider LHW, Hrassnigg N, Bühlmann G, Brosch U, Gmeinbauer R, Schöffmann B (1992) Pollen consumption and utilization in worker honeybees (Apis mellifera carnica): dependence on individual age and function. J Insect Physiol 38:409-419. doi:https://doi.org/10.1016/0022-1910(92)90117-V
Cremonz TM, De Jong D, Bitondi MMG (1998) Quantification of hemolymph proteins as a fast method for testing protein diets for honey bees (Hymenoptera: Apidae). J Econ Entomol 91:1284-1289. doi:https://doi.org/10.1093/jee/91.6.1284

De Jong D, da Silva EJ, Kevan PG, Atkinson JL (2009) Pollen substitutes increase honey bee haemolymph protein levels as much as or more than does pollen. $\mathrm{J}$ Apic Res 48:34-37. doi:https://doi.org/10.3896 /ibra.1.48.1.08

Dechaume Moncharmont FX, Decourtye A, HennequetHantier C, Pons O, Pham-Delegue MH (2003) Statistical analysis of honeybee survival after chronic exposure to insecticides. Environ Toxicol Chem 22:30883094. doi:https://doi.org/10.1897/02-578

Di Pasquale G, Salignon M, Le Conte Y, Belzunces LP, Decourtye A, Kretzschmar A, Suchail S, Brunet JL, Alaux C (2013) Influence of pollen nutrition on honey bee health: do pollen quality and diversity matter? PLoS One 8:e72016-e72028. doi:https://doi. org/10.1371/journal.pone.0072016

Elzen PJ, Baxter JR, Neumann P, Solbrig A, Pirk C, Hepburn HR, Westervelt D, Randall C (2001) Behaviour of African and European subspecies of Apis mellifera toward the small hive beetle, Aethina tumida. J Apic Res 40:40-41. doi:https://doi.org/10.1080 /00218839.2001.11101049

Evans J, Chen YP, di Prisco GdP, Pettis J, Williams V (2009) Bee cups: single-use cages for honey bee experiments. J Apic Res 48:300-302. doi:https://doi. org/10.3896/ibra.1.48.4.13

Goulson D, Nicholls E, Botias C, Rotheray EL (2015) Bee declines driven by combined stress from parasites, pesticides, and lack of flowers. Science 347:12559571255967. doi:https://doi.org/10.1126/science.1255957

Gregorc A, Alburaki M, Rinderer N, Sampson B, Knight PR, Karim S, Adamczyk J (2018) Effects of coumaphos and imidacloprid on honey bee (Hymenoptera: Apidae) lifespan and antioxidant gene regulations in laboratory experiments. Scientific reports 8:1500315015. doi:https://doi.org/10.1038/s41598-01833348-4

Grozinger CM, Sharabash NM, Whitfield CW, Robinson GE (2003)Pheromone-mediated gene expression in the honey bee brain. Proc Natl Acad Sci USA 100:1451914525. doi:https://doi.org/10.1073/pnas.2335884100

Hendriksma HP, Pachow CD, Nieh JC (2019) Effects of essential amino acid supplementation to promote honey bee gland and muscle development in cages and colonies. J Insect Physiol 117:103906-103913. doi:https://doi.org/10.1016/j.jinsphys.2019.103906

Huang SK, Csaki T, Doublet V, Dussaubat C, Evans JD, Gajda AM, Gregorc A, Hamilton MC, Kamler M, Lecocq A, Muz MN, Neumann P, Özkirim A, Schiesser A, Sohr AR, Tanner G, Tozkar CÖ, Williams GR, Wu L, Zheng H, Chen YP (2014) Evaluation of cage designs and feeding regimes for honey bee (Hymenoptera: Apidae) laboratory experiments. J Econ Entomol 107:54-62. doi:https://doi.org/10.1603 /ec13213 
Köhler A, Nicolson SW, Pirk CWW (2013) A new design for honey bee hoarding cages for laboratory experiments. J Apic Res 52:12-14. doi:https://doi. org/10.3896/IBRA.1.52.2.03

Liolios V, Tananaki C, Dimou M, Kanelis D, Goras G, Karazafiris E, Thrasyvoulou A (2016) Ranking pollen from bee plants according to their protein contribution to honey bees. J Apic Res 54:582-592. doi:https://doi. org/10.1080/00218839.2016.1173353

Livak KJ, Schmittgen TD (2001) Analysis of relative gene expression data using real-time quantitative PCR and the $2^{-\Delta \Delta C T}$ method. Methods 25:402-408. doi:https://doi.org/10.1006/meth.2001.1262

Lourenço A, Pedro, Mackert A, dos Santos Cristino A, Simões Z, Luz Paulino (2008) Validation of reference genes for gene expression studies in the honey bee, Apis mellifera, by quantitative real-time RT-PCR. Apidologie 39:372-385. doi:https://doi.org/10.1051 /apido:2008015

Manning R (2006) Fatty acid composition of pollen and the effect of two dominant fatty acids (linoleic and oleic) in pollen and flour diets on longevity and nutritional composition of honey bees (Apis mellifera). Murdoch University

Martin-Hernandez R, Meana A, Garcia-Palencia P, Marin P, Botias C, Garrido-Bailon E, Barrios L, Higes M (2009) Effect of temperature on the biotic potential of honeybee microsporidia. Appl Environ Microbiol 75:2554-2557. doi:https://doi.org/10.1128 /AEM.02908-08

Omar E, Abd-Ella AA, Khodairy MM, Moosbeckhofer R, Crailsheim K, Brodschneider R (2017) Influence of different pollen diets on the development of hypopharyngeal glands and size of acid gland sacs in caged honey bees (Apis mellifera). Apidologie 48:425-436. doi:https://doi.org/10.1007/s13592-0160487-X

Peng Y, D'Antuono M, Manning R (2012) Effects of pollen and artificial diets on the hypopharyngeal glands of newly hatched bees (Apis mellifera L.). J Apic Res 51:53-62. doi:https://doi.org/10.3896/ibra.1.51.1.07

Rahman S, Thangkhiew I, Hajong SR (2014) Hypopharyngeal gland activity in task-specific workers under brood and broodless conditions in Apis cerana indica (fab.). J Apic Sci 58:59-70. doi:https://doi.org/10.2478/jas-2014-0022

Ricigliano VA, Mott BM, Maes PW, Floyd AS, Fitz W, Copeland DC, Meikle WG, Anderson KE (2019) Honey bee colony performance and health are enhanced by apiary proximity to US Conservation Reserve Program (CRP) lands. Scientific reports 9:4894-4905. doi:https://doi.org/10.1038/s41598-019-41281-3
Scharlaken B, de Graaf DC, Goossens K, Brunain M, Peelman LJ, Jacobs FJ (2008) Reference gene selection for insect expression studies using quantitative real-time PCR: The head of the honeybee, Apis mellifera, after a bacterial challenge. J Insect Sci 8:110. doi:https://doi.org/10.1673/031.008.3301

Steinhauer N, Kulhanek K, Antunez K, Human H, Chantawannakul P, Chauzat MP, vanEngelsdorp D (2018) Drivers of colony losses. Curr Opin Insect Sci 26:142-148. doi:https://doi.org/10.1016/j. cois.2018.02.004

Tosi S, Nieh JC (2017) A common neonicotinoid pesticide, thiamethoxam, alters honey bee activity, motor functions, and movement to light. Scientific reports 7:15132-15144. doi:https://doi.org/10.1038/s41598017-15308-6

van der Steen J (2007) Effect of a home-made pollen substitute on honey bee colony development. J Apic Res 46:114-119. doi:https://doi.org/10.3896 /ibra.1.46.2.09

Williams GR, Alaux C, Costa C, Csáki T, Doublet V, Eisenhardt D, Fries I, Kuhn R, McMahon DP, Medrzycki P, Murray TE, Natsopoulou ME, Neumann P, Oliver R, Paxton RJ, Pernal SF, Shutler D, Tanner G, van der Steen JJM, Brodschneider R (2013) Standard methods for maintaining adult Apis mellifera in cages under in vitro laboratory conditions. J Apic Res 52:1-36. doi:https://doi.org/10.3896/ibra.1.52.1.04

Wright GA, Nicolson SW, Shafir S (2018) Nutritional physiology and ecology of honey bees. Annu Rev Entomol 63:327-344. doi:https://doi.org/10.1146 /annurev-ento-020117-043423

Wu JY, Anelli CM, Sheppard WS (2011)Sub-lethal effects of pesticide residues in brood comb on worker honey bee (Apis mellifera) development and longevity. PLoS One 6:e14720-e14730. doi:https://doi.org/10.1371 /journal.pone.0014720

Wu MC, Chang YW, Lu KH, Yang EC (2017) Gene expression changes in honey bees induced by sublethal imidacloprid exposure during the larval stage. Insect Biochem Mol Biol 88:12-20. doi:https://doi. org/10.1016/j.ibmb.2017.06.016

Zheng H, Powell JE, Steele MI, Dietrich C, Moran NA (2017) Honeybee gut microbiota promotes host weight gain via bacterial metabolism and hormonal signaling. Proc Natl Acad Sci U S A 114:4775-4780. doi:https://doi.org/10.1073/pnas.1701819114

Publisher's note Springer Nature remains neutral with regard to jurisdictional claims in published maps and institutional affiliations. 